\title{
Pre-clinical study of IRDye800CW- nimotuzumab formulation, stability, pharmacokinetics, and safety
}

\author{
Wendy Bernhard', Kris Barreto', Ayman El-Sayed', Carolina Gonzalez', Raja Solomon Viswas², Darien Toledo ${ }^{3}$, \\ Angel Casaco ${ }^{3}$, John DeCoteau', Humphrey Fonge ${ }^{2,4^{*}}$ and Clarence Ronald Geyer ${ }^{1 *}$ (D)
}

\begin{abstract}
Background: Epidermal growth factor receptor (EGFR) is a target for cancer therapy as it is overexpressed in a wide variety of cancers. Therapeutic antibodies that bind EGFR are being evaluated in clinical trials as imaging agents for positron emission tomography and image-guided surgery. However, some of these antibodies have safety concerns such as infusion reactions, limiting their use in imaging applications. Nimotuzumab is a therapeutic monoclonal antibody that is specific for EGFR and has been used as a therapy in a number of countries.

Methods: Formulation of IRDye800CW-nimotuzumab for a clinical trial application was prepared. The physical, chemical, and pharmaceutical properties were tested to develop the specifications to determine stability of the product. The acute and delayed toxicities were tested and IRDye800CW-nimotuzumab was determined to be nontoxic. Non-compartmental pharmacokinetics analysis was used to determine the half-life of IRDye800CW-nimotuzumab.

Results: IRDye800CW-nimotuzumab was determined to be non-toxic from the acute and delayed toxicity study. The half-life of IRDye $800 \mathrm{CW}$-nimotuzumab was determined to be $38 \pm 1.5 \mathrm{~h}$. A bi-exponential analysis was also used which gave a $t_{1 / 2}$ alpha of $1.5 \mathrm{~h}$ and $\mathrm{t}_{1 / 2}$ beta of $40.8 \mathrm{~h}$.

Conclusions: Here, we show preclinical studies demonstrating that nimotuzumab conjugated to IRDye800CW is safe and does not exhibit toxicities commonly associated with EGFR targeting antibodies.
\end{abstract}

Keywords: Nimotuzumab, EGFR, Near-infrared fluorescence imaging, IRDye800CW, Image-guided surgery,

Investigator's brochure

\section{Background}

The purpose of this study is to prepare the required information package for an ICH E6(R2) Investigator's Brochure (IB), which is part of a clinical trial application (CTA) or an investigational new drug application (IND) for image-guided surgery with IRDye800CWnimotuzumab. This clinical trial is currently ongoing

\footnotetext{
* Correspondence: humphrey.fonge@usask.ca; ron.geyer@usask.ca ${ }^{2}$ Department of Medical Imaging, College of Medicine, University of Saskatchewan, Saskatoon, SK, Canada

'Department of Pathology and Laboratory Medicine, College of Medicine, University of Saskatchewan, Saskatoon, SK, Canada

Full list of author information is available at the end of the article
}

(NCT04459065). The IB is composed of the following seven sections (Fig. 1): (i) Table of Contents, (ii) Summary, (iii) Introduction, (iv) Physical, Chemical, and Pharmaceutical Properties and Formulation, (v) Nonclinical Studies, (vi) Effects in Humans, and (vii) Summary of Data and Guidance for the Investigator. Data required for Section 4: Physical, Chemical, and Pharmaceutical Properties and Formulation, Section 5: Nonclinical Studies, and Section 6: Effects in Humans are discussed.

The investigational product for this study was IRDye800CW-nimotuzumab, which was developed as an imaging agent for use in image-guided surgery.

C C The Author(s). 2021 Open Access This article is licensed under a Creative Commons Attribution 4.0 International License, which permits use, sharing, adaptation, distribution and reproduction in any medium or format, as long as you give appropriate credit to the original author(s) and the source, provide a link to the Creative Commons licence, and indicate if changes were made. The images or other third party material in this article are included in the article's Creative Commons licence, unless indicated otherwise in a credit line to the material. If material is not included in the article's Creative Commons licence and your intended use is not permitted by statutory regulation or exceeds the permitted use, you will need to obtain permission directly from the copyright holder. To view a copy of this licence, visit http://creativecommons.org/licenses/by/4.0/ The Creative Commons Public Domain Dedication waiver (http://creativecommons.org/publicdomain/zero/1.0/) applies to the data made available in this article, unless otherwise stated in a credit line to the data. 


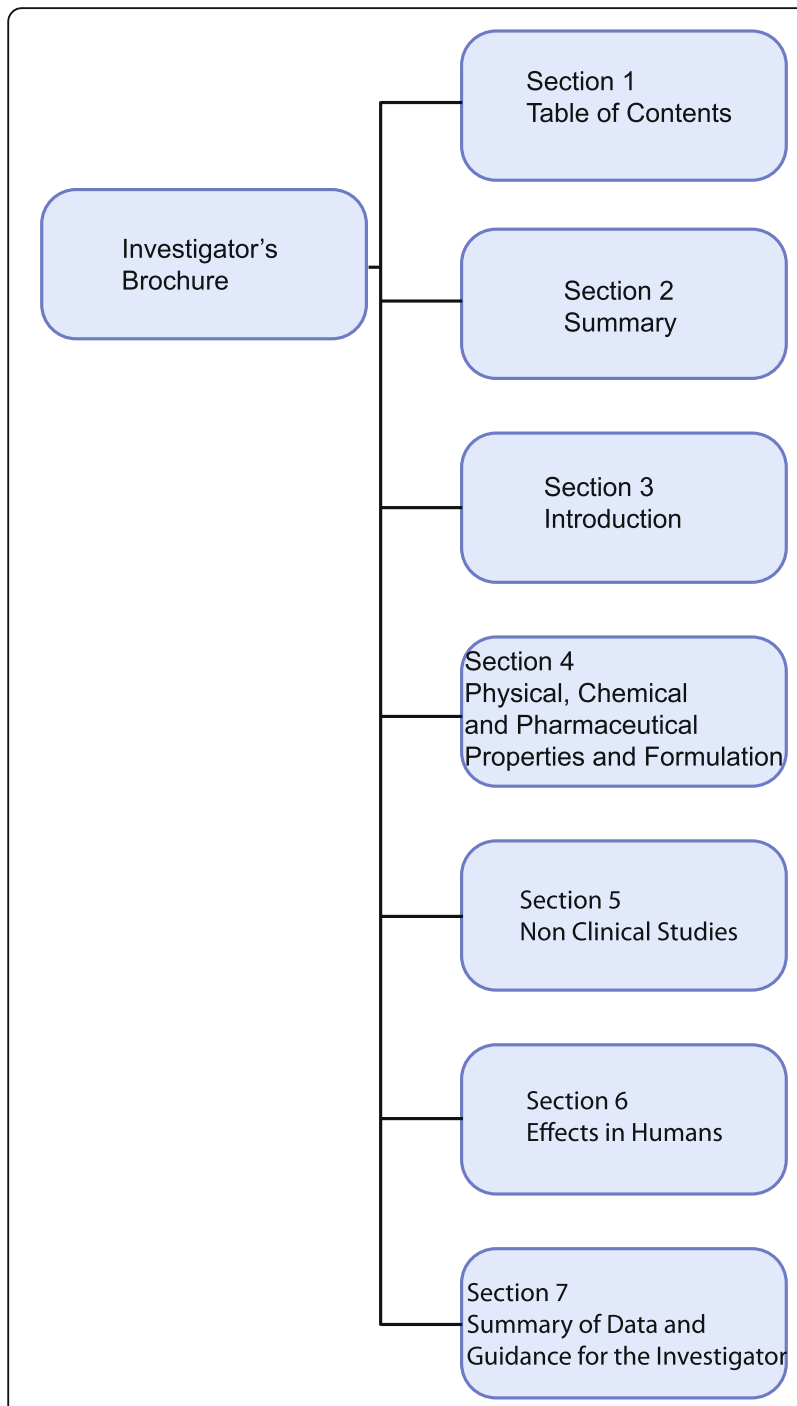

Fig. 1 Investigator's Brochure schematic. Sections 1-7 of the Investigator's brochure

IRDye800CW-nimotuzumab was constructed by conjugating the near-infrared fluorescent molecule IRDye800CW-NHS ester to the monoclonal antibody nimotuzumab to produce the active pharmacological ingredient IRDye800CW-nimotuzumab. IRDye800CW has an absorbance maximum at $774 \mathrm{~nm}$ and emission maximum at $789 \mathrm{~nm}$ in PBS, which acts as a fluorescent contrast agent that specifically accumulates on EGFR positive tumors when conjugated to an EGFR specific probe. IRDye $800 \mathrm{CW}$-nimotuzumab targets cancer cells, which overexpress EGFR, allowing EGFR positive tumors to be visualized during surgery. EGFR is a cell surface glycoprotein that regulates cell proliferation, survival, and differentiation [1]. Activation of EGFR normally leads to cellular growth, however aberrant activation caused by receptor overexpression, autocrine signalling, or mutation can lead to the development of tumors [1]. EGFR is overexpressed in a number of cancers, particularly in tissue of epithelial origin, including glioma, head and neck, lung, breast, renal, bladder, and prostate cancer [2].

Image-guided surgery is a technology that was developed to improve tumor resection [3]. Currently tumor resection relies on images taken before surgery by computed tomography (CT), positron emission tomography (PET), or magnetic resonance imaging (MRI) [4]. It can be difficult to define tumor margins using static images collected prior to surgery using CT, PET, and/or MRI [4]. Defining tumors using white light illumination and visual inspection can lead to inadequate resection, tumor re-occurrence, and additional surgery(s) [4]. IRDye $800 \mathrm{CW}$-nimotuzumab specifically targets EGFRpositive tumors, allowing them to be distinguished from normal surrounding tissue in real-time using nearinfrared (NIR) fluorescent imaging. This results in decreased damage to healthy tissue and operation time. In addition, after resection the wound bed can be imaged to determine if there is residual fluorescent malignant tissue, which can then be removed immediately as opposed to waiting for histopathological analysis and a potential second surgery. Targeted imaging agents are designed to specifically recognize molecules expressed on cancer cells like receptors, leading to higher tumor to background ratios.

IRDye800CW-nimotuzumab shares structural similarities to other known IRDye800CW-conjugated probes in clinical trials (Additional File 1), including IRDye800CWbevacizumab, IRDye800CW-panitumumab, and IRDye800CWcetuximab. The anti-EGFR antibodies panitumumab and cetuximab are labeled with IRDye800CW and used successfully in image-guided surgery clinical trials to identify EGFR-positive tissues [5, 6]. These EGFR imaging probes show minimal adverse events when patients receive a loading dose of the unlabeled antibody prior to the injection of the imaging probe [7].

Nimotuzumab is marketed and has been administered to over 38,000 patients with limited adverse events reported [8]. Compared to other anti-EGFR antibodies (cetuximab and panitumumab), nimotuzumab has a superior safety profile, particularly with regard to serious cutaneous toxicities [9]. For example, $\sim 80 \%$ of participants from four different cetuximab studies developed a skin rash that is associated with cetuximab with some grade 3 skin toxicities reported [9]. Panitumumab therapy resulted in $68,95,87$, and $100 \%$ of patients developing skin rash, depending on the dose [9]. In another study, $95 \%$ of patients develop skin toxicities, with some grade 3 skin toxicities reported [9]. In comparison, one clinical trial with nimotuzumab reported that $6 \%$ of patients developed grade 1 or 2 level skin rash with no 
grade 3 or 4 level skin toxicities [9]. Further, IRDye $800 \mathrm{CW}$ is non-toxic [10].

In this study, we present the formulation and stability of IRDye800CW-nimotuzumab required for Section 4 of the IB and the preclinical safety and pharmacokinetics for Section 5 of the IB. Since IRDye800CWnimotuzumab has not been injected into humans before to address Section 6: Effects in Humans, we performed a meta-analysis of clinical trials on other IRDye800CWconjugated antibodies, summarizing indications tested, geographical locations where clinical trials were performed, and adverse events reported.

\section{Methods}

\section{Reagents}

Nimotuzumab was provided by the Center of Molecular Immunology (CIM) (Havana, Cuba). IRDye ${ }^{\bullet}$ 800CWNHS ester was supplied by LI-COR Biosciences (Lincoln, $\mathrm{NE})$.

\section{Conjugation of IRDye800CW to nimotuzumab}

Four batches of nimotuzumab, each containing five milligrams, were labeled with IRDye $800 \mathrm{CW}$ NHS Ester at a 1:3 (nimotuzumab: IRDye800CW) molar ratio in $1 \mathrm{X}$ PBS, $\mathrm{pH} 7.0$, with rotation at room temperature for one hour. Unincorporated IRDye800CW was removed using a Zeba spin desalting column $7 \mathrm{~K}$ MWCO (ThermoFisher Scientific). IRDye800CW-nimotuzumab solution was sterilized using a $0.22 \mu \mathrm{m}$ Ultrafree centrifugal filter (EMD Millipore). The concentration and labeling efficiency were calculated as previously reported [11]. IRDye $800 \mathrm{CW}$-nimotuzumab was aliquoted and stored at $-80^{\circ} \mathrm{C}$. Batches $1-3$ were used for stability testing and batch 4 was used for toxicity studies. Batch 4 was diluted in a final volume of $200 \mu \mathrm{L}$ of $0.9 \%$ saline prior to injection.

\section{Purity and molecular weight analysis of IRDye800CW- nimotuzumab}

The purity and molecular weight of labeled and unlabeled nimotuzumab were analyzed using microcapillary electrophoresis with an Agilent 2100 Bioanalyzer (Agilent Technologies, Santa Clara, CA), according to the manufacturer's instructions.

\section{Stability of IRDye800CW-nimotuzumab}

Batches 1-3 of IRDye800CW-nimotuzumab were stored at $-80^{\circ} \mathrm{C}$ and $4{ }^{\circ} \mathrm{C}$. Stability of the IRDye $800 \mathrm{CW}$ nimotuzumab was tested over time for size and purity using microcapillary electrophoresis (Bioanalyzer), according to the manufacturer's instructions. Stability was determined as described in Stability testing of new drug substances and products ICH Q1A(R2) [12], where the 95\% confidence interval intersects with the acceptance criteria. The $\mathrm{pH}$ was determined using a Thermo Scientific $^{\text {tw }}$ Orion $^{\text {tw }}$ Star A211 pH Benchtop Meter. The $\mathrm{pH}$ meter was calibrated at each use. Fluorescence purity was determined using SDS-PAGE where $5 \mu \mathrm{L}$ of sample diluted 2000-fold in PBS was separated on a 4-20\% Mini-PROTEAN ${ }^{\diamond}$ TGX $^{\text {ma }}$ Precast Protein Gels for $200 \mathrm{~V}$ for $25 \mathrm{~min}$. Volume was determined at the time of dispensing using a scale. Sterility was validated and measured by Keystone Labs Inc. and endotoxin was measured by the Fedoruk Center. Flow cytometry was performed on A-431 with unlabeled and four labeled IRDye800CW-nimotuzuamb batches as previously described [11].

\section{Mouse xenograft models and in vivo imaging}

All mice used in this study were commercially obtained from Charles River Canada and housed in accordance with the University Animal Care Committee (UACC) guidelines (protocol \# 20150048). All experiments and euthanasia were performed in accordance with UACC guidelines. All animals were acclimatized for 1 week prior to use. Mice used in all experiments except for toxicity were euthanized using carbon dioxide followed by cervical dislocation. For toxicity mice were anaesthetized with $3 \%$ isoflurane and euthanized by exsanguination via cardiac puncture to collect blood for hematology and clinical chemistry. Mice were anesthetized with $3 \%$ isoflurane for xenograft implantation and imaging experiments. CD-1 nude female mice were used for fluorescent imaging. For imaging experiments, HT29, MDA-MB-468, and MDA-MB-435 xenografts were prepared by injecting $10^{7}$ cells suspended in $50 \mu \mathrm{L}$ of serum free media and mixed with $50 \mu \mathrm{L}$ of Matrigel basement matrix (Corning) into the right hind flank of 4-6 week old female CD-1 nude mice. Xenografts were monitored with external calipers until they reached $150-300 \mathrm{~mm}^{3}$. 0.5 nmoles of IRDye800CW-nimotuzumab was intravenously injected in the tail vein of mice bearing HT29, MDA-MB-468 or MDA-MB-435 xenografts. Mice were imaged 72 and $168 \mathrm{~h}$ post injection on a Pearl small animal imager (LI-COR). The EGFR positive xenografts (HT29 and MDA-MB-468) were compared to the negative control xenograft (MDA-MB-435). Each experimental unit had at least three mice $(n=3)$ that were imaged for each xenograft for a total of at least nine mice used for the imaging experiments to get statistically relevant values. No animals and no images were excluded. Mice were randomised based on tumor size to ensure all mice had the same size tumors. There was no blinding in the imaging experiment and confounders were controlled by imaging the animals in the same order. Health and behaviour of the mice were analyzed daily. 


\section{Pharmacokinetics}

Twelve 4-6 week old female Balb/c mice were injected intravenously via the tail vein with 0.5 nmole $(75 \mu \mathrm{g})$ of IRDye800CW-nimotuzumab. Blood was collected from four mice $(n=4)$ after $10 \mathrm{~min}, 1,3,6,24,48,72,96,168$, and $240 \mathrm{~h}$, and four mice $(\mathrm{n}=4)$ after $5,15,30$, and 45 min. Four mice $(n=4)$ were used as a negative control to determine pharmacokinetics. Blood samples were collected from the tail vein in a heparinized capillary tube and the fluorescence was measured using the LI-COR Odyssey scanner. The concentration of IRDye $800 \mathrm{CW}$ nimotuzumab was determined using a series of standards in heparinized capillary tubes to generate a calibration curve. No prior criteria were determined to exclude animals and no data collected was excluded. No randomization or blinding was used, and mice were bled in the same order for data point collection to reduce confounders. Mice were analyzed for health and behavior daily. Non-compartmental and bi-exponential analysis was performed using the $\mathrm{R}$ [13] package PK [14]. Bi-exponential and non-compartmental models with i.v. bolus input was used to fit pharmacokinetic parameters including area under the curve (AUC), volume of distribution at steady-state (Vss), clearance (CL), and half-life.

\section{Single dose toxicity study}

A single dose of 2 nmoles of IRDye $800 \mathrm{CW}$ nimotuzumab was injected via the tail vein of 7-8 week old BALB/c mice to determine acute (day 2) and delayed (day 14) toxicity. All animals in this study were observed regularly for signs of mortality, morbidity, injury, and intake of food and water. Mice were monitored for weight loss and daily clinical observation. Individual body weights were determined and recorded 5 days a week during quarantine and the study period. It was decided prior to the study that animals that started to lose weight before injection would not be included in the study, however no animals were excluded. Forty-eight mice (24 male +24 female) were divided into five groups (Table 1). Eight mice were used as a baseline control. Four of these mice were sacrificed for acute toxicity baseline at day 2 and four mice for delayed toxicity baseline at day 14. Twenty mice (control group) were treated with saline as the vehicle control. Ten of these mice were sacrificed as controls for acute toxicity at day 2 and ten mice were sacrificed as controls for delayed toxicity at day 14 . Twenty mice (treatment group) were injected with 2 nmoles $(300 \mu \mathrm{g})$ of IRDye $800 \mathrm{CW}$-nimotuzumab (batch 4). Ten of these mice were sacrificed for acute toxicity analysis on day 2 and ten mice were sacrificed for delayed toxicity analysis on day 14 . There was no randomization or blinding in this study and all animals were collected in the order they were injected within the two time points to minimize confounders.

Organs/tissues (kidneys, spleen, liver, bone, heart, lungs, brain, skin, muscle, and testes/uterus) were inspected, collected, and stored in $10 \%$ neutral buffered formalin. Mouse identification was retained with tissues taken during necropsy. The liver, spleen, and kidney were weighed and processed on slides for histopathology evaluation. Samples of each tissue were embedded in paraffin blocks and representative $7 \mu \mathrm{m}$ sections were mounted on glass microscope slides, stained with hematoxylin and eosin, and the histopathology reviewed by a board-certified pathologist.

Blood was collected while mice were anesthetized with $3 \%$ isoflurane prior to euthanasia by exsanguination via cardiac puncture for hematology and clinical chemistry. Blood $(50 \mu \mathrm{L})$ was collected in a K2 EDTA coated tube for hematology. K2 EDTA coated tubes were made by adding $2.5 \mu \mathrm{L}$ of a $50 \mathrm{mM}$ stock solution of $\mathrm{K} 2$ EDTA. The tubes were dried in a biosafety cabinet overnight. A complete blood count was done on the whole blood samples. A minimum of $500 \mu \mathrm{L}$ of blood was collected for clinical chemistry analysis into microvette $500 \mathrm{LH}$ heparin-coated tubes (Sarstedt AG \& Co). Blood was inverted 8 times and centrifuged at $1500 \mathrm{x}$ g for $10 \mathrm{~min}$. Plasma was collected and sent to Prairie Diagnostic Services (Saskatoon, SK) for clinical chemistry analysis.

Analyses of the clinical chemistry and hematology parameters for differences in means were performed using a non-parametric Kruskal-Wallis test. If a statistically significant difference was present $(p<0.05)$ then comparisons between the vehicle control and treatment groups and baseline and treatment groups were performed using the Dunn's test. Differences were

Table 1 Single dose acute and delayed study design

\begin{tabular}{|c|c|c|c|c|c|}
\hline Group & Mice/group & Sex & Compound & Collected $^{\mathrm{a}}$ at day 2 & Collected $^{\mathrm{a}}$ at day 14 \\
\hline Untreated control & 4 & $\mathrm{~F}$ & None & 2 & 2 \\
\hline Untreated control & 4 & M & None & 2 & 2 \\
\hline Vehicle Control & 10 & $\mathrm{~F}$ & Saline & 5 & 5 \\
\hline Vehicle control & 10 & M & Saline & 5 & 5 \\
\hline 2 nmoles IRDye800CW-nimotuzumab & 10 & $\mathrm{~F}$ & 15 mg/kg IRDye800CW-nimotuzumab & 5 & 5 \\
\hline 2 nmoles IRDye800CW-nimotuzumab & 10 & M & 15 mg/kg IRDye800CW-nimotuzumab & 5 & 5 \\
\hline
\end{tabular}


considered statistically significant if $\mathrm{p}<0.05$ between the treatment group and both vehicle and baseline groups. Statistical analysis was performed using $\mathrm{R}$ project for statistical computing.

\section{Meta-analysis of clinical trial data of IRDye800CW}

A search on pubmed was performed as described in Additional File 2, using search terms "800CW" or "IRDye 800CW" with the clinical trials filter applied. Additional searches for principal investigators involved in clinical trials combined with the search term IRDye $800 \mathrm{CW}$ resulted in 51 publications. These publications were manually curated for those discussing clinical trials, resulting 17 papers 8 of which contained results on adverse events (Additional File 2).

\section{Results}

\section{Physical, chemical, and pharmaceutical properties and} formulation

The drug substance IRDye800CW-nimotuzumab was made by conjugating the NHS ester IRDye800CW to nimotuzumab. The drug product is formulated in the excipient $0.9 \%$ saline for injection. We prepared four different batches of IRDye800CW-nimotzumab. The average labeling ratio of IRDye800CW to nimotuzumab was $1.29 \pm 0.03$. Protein impurities were assessed by microcapillary electrophoresis. The average purity was $98.9 \pm$ $0.2 \%$. One batch was used for toxicity studies and the other three batches were used to determine stability (Fig. 2). Batches were stable with purities of $>95 \%$ for 270 days (9 months) when stored at $-80^{\circ} \mathrm{C}$ and one week when stored at $4{ }^{\circ} \mathrm{C}$.

To assess whether the conjugate IRDye800CWnimotuzumab was functional, samples were tested for binding to the EGFR positive cell line A-431 using flow cytometry. All four batches of IRDye800CWnimtotuzumab bound to the A-431 cell line with the following affinities: Batch $1=9 \pm 2 \mathrm{nM}$, Batch $2=10 \pm 1$ $\mathrm{nM}$, Batch $3=12 \pm 3 \mathrm{nM}$, and Batch $4=12 \pm 2 \mathrm{nM}$ (Fig. 3). There were no significant differences $(p>0.05)$ between $K_{D}$ values of batches. Labeling nimotuzumab with IRDye800CW did not have a significant affect ( $\mathrm{p}$ > 0.05 ) on its ability to bind to A-431 when compared to the unlabeled antibody $\left(K_{D}\right.$ of $\left.10.5 \pm 0.7 \mathrm{nM}\right)$.

Nimotuzumab-IRDye800CW accumulated in EGFR positive xenografts generated from HT29 and MDAMB-468 cell lines and not in the EGFR- negative xenograft generated from MDA-MB-435 (Fig. 4). We previously showed that MDA-MB-435 has very low EGFR expression and the levels of EGFR expression are similar in HT29 and MDA-MB-468 cell lines [11].

The batches of IRDye800CW-nimotuzumab were reproducibly prepared at high purity. There was no significant difference in the affinities to EGFR positive cells

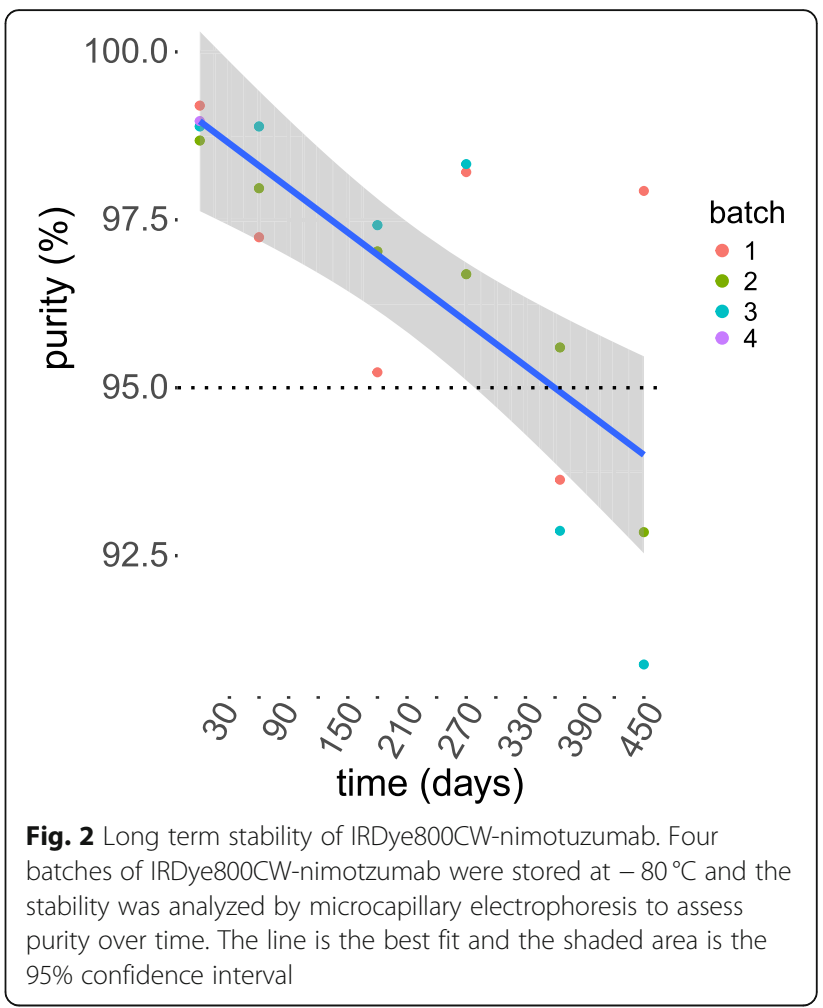

between any of the batches produced or between the batches and unlabeled nimotuzumab, indicating the robustness of the formulation process. The probe was stable for nine months when stored at $-80^{\circ} \mathrm{C}$ and for one week when stored at $4{ }^{\circ} \mathrm{C}$, which gives a starting point for determining the shelf-life. This information was used to define specifications (Table 2).

\section{Nonclinical studies: pharmacokinetics of IRDye800CW- nimotuzumab}

Pharmacokinetics of IRDye800CW-nimotuzumab was studied in normal $\mathrm{BALB} / \mathrm{c}$ mice. Twelve mice were injected with 0.5 nmoles $(75 \mu \mathrm{g})$ of IRDye800CWnimotuzumab. Blood was collected over time and the mean fluorescence was measured and analyzed using biexponential and non-compartmental analyses. IRDye800CW-nimotuzuamb has a non-compartmental half-life of $38 \pm 1.5 \mathrm{~h}$. Area under the curve (AUC) was $36 \pm 2 \mu \mathrm{g} \cdot$ day $/ \mathrm{mL}$ and AUC to infinity was $35.7 \mu \mathrm{g} \cdot$ day $/$ $\mathrm{mL}$. Clearance (CL) was $2 \pm 1 \mathrm{~mL} /$ day and volume of distribution at steady state (Vss) was $4.8 \pm 0.2 \mathrm{~mL}$. The pharmacokinetics of IRDye800CW-nimotuzumab was also analyzed by a bi-exponential analysis (Fig. 5), which gave a $t_{1 / 2}$ alpha of $1.5 \mathrm{~h}$ and $t_{1 / 2}$ beta of $40.8 \mathrm{~h}$. The AUC was $34.5 \mu \mathrm{g} \bullet$ day $/ \mathrm{mL}$. The systemic clearance (CL) was $2.2 \mathrm{~mL} /$ day and the volume distribution at steady state (Vss) was calculated to be $5.3 \mathrm{~mL}$. 

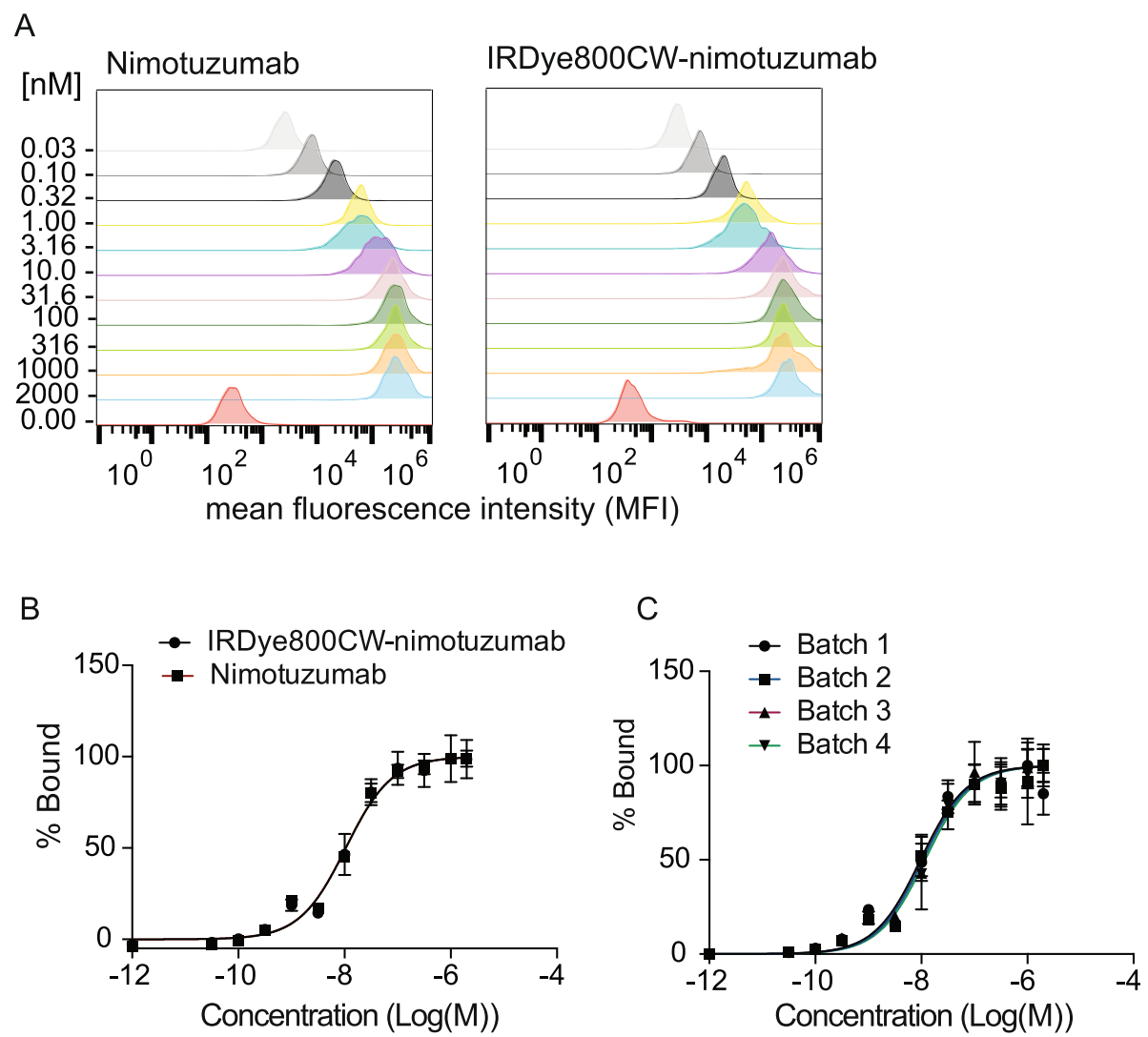

Fig. 3 Binding studies of IRDye800CW-nimotuzumab with A-431 cells. Unlabeled nimotuzumab and four batches of IRDye800CW-nimotuzumab were tested for binding to the EGFR positive cell line A-431 using flow cytometry to test reproducibility of batch formulation. $\mathbf{a}$ and $\mathbf{b}$ show IRDye800CW-nimotuzumab binding compared to unlabeled nimotuzumab. c Batch-to-batch variability of IRDye800CW-nimotuzumab in cell binding. The error bars represent the standard deviation

\section{Nonclinical studies: acute and delayed toxicity of IRDye800CW-nimotuzumab}

Single does acute (2-day) and delayed (14-day) toxicity of IRDye800CW-nimotuzumab were studied in normal BALB/c mice. Groups of mice were treated as shown in Table 1. Saline was injected as the vehicle control and untreated mice were used as a baseline. Mice were monitored and weighed daily one week before and for the duration of the study (Additional File 3). No significant weight gain or loss was observed between the IRDye800CW-nimotuzumab and vehicle or baseline groups during the study. All animals survived to the scheduled necropsy. There was no apparent anemia, weight loss, agitation, tachypnea, GI disturbances, or neurological dysfunction in any of the mice groups. All mice looked healthy and displayed normal behavior throughout. Tissues were collected for histopathology and blood was collected for CBC and clinical chemistry.

Major organs (liver, spleen, kidney, heart, brain, lungs, muscle, skin, bone, and uterus/testis) were collected. The liver, spleen, and kidney were weighed (Additional File 4) and processed for histopathological analysis. There was no significant difference in organ weight between treatment groups $(p>0.05)$. Histopathological examination of necropsy stained slices showed no damage to organs following administration of 2 nmoles of IRDye800CW-nimotuzumab (a 25-fold mass excess of the projected human dose). Single dose acute (2 Day) and delayed (14 Day) toxicity analysis showed that IRDye800CW-nimtuzumab was non-toxic in normal $\mathrm{BALB} / \mathrm{c}$ mice.

To assess the clinical chemistry for toxicity of IRDye800CW-nimotuzumab, blood was collected via cardiac puncture and the plasma was separated and analyzed. At both 2 days and 14 days post injection there were no differences in the means $(p>0.05)$ of any of the blood chemistry parameters in females or males when the treatment groups were compared to the baseline and vehicle group. These results are summarized in Tables 3 , Table 4 and Additional File 5.

To assess hematology toxicity of IRDye800CWnimotuzumab, blood was collected after injection via cardiac puncture on day 2 or day 14 . Whole blood was tested and analyzed for complete blood counts (CBC). 


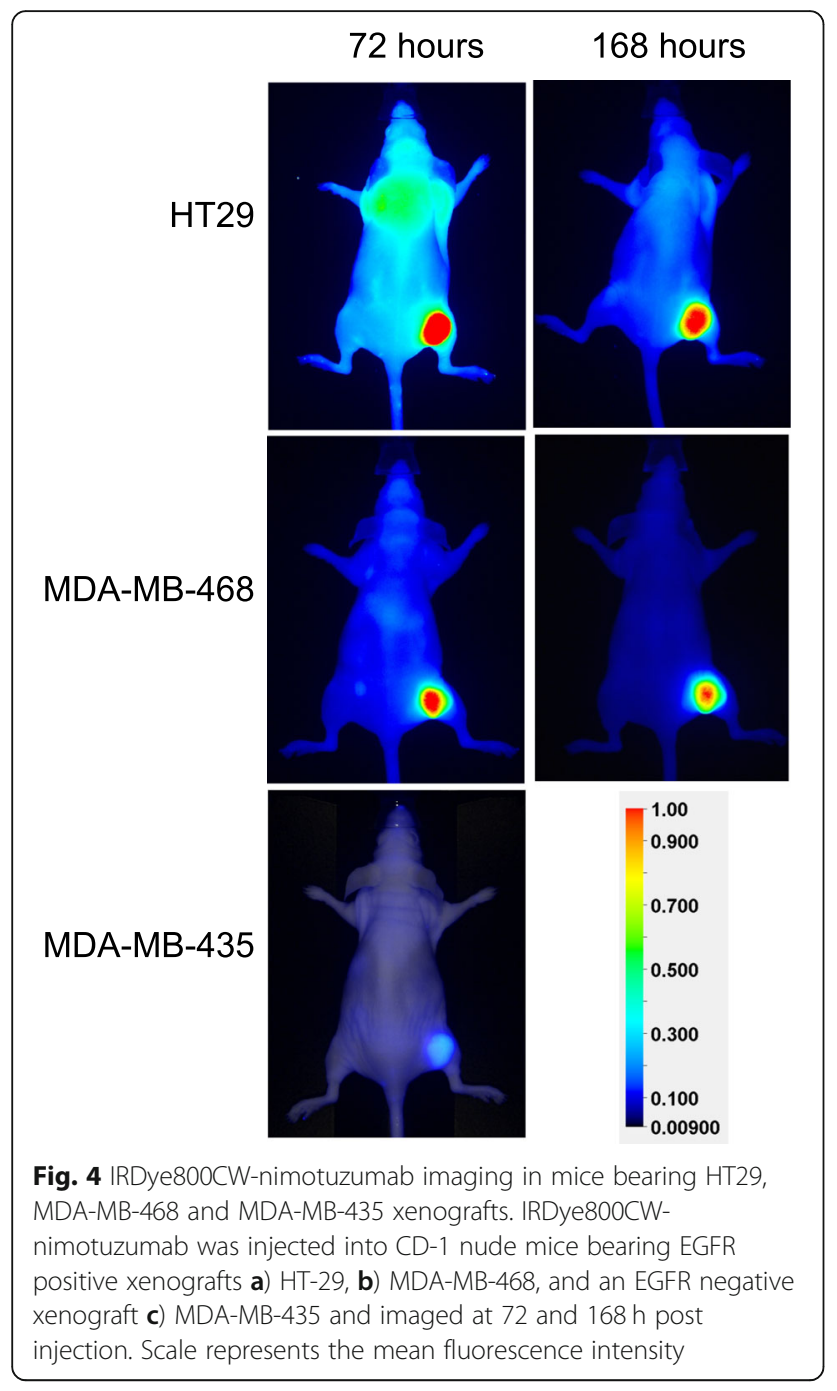

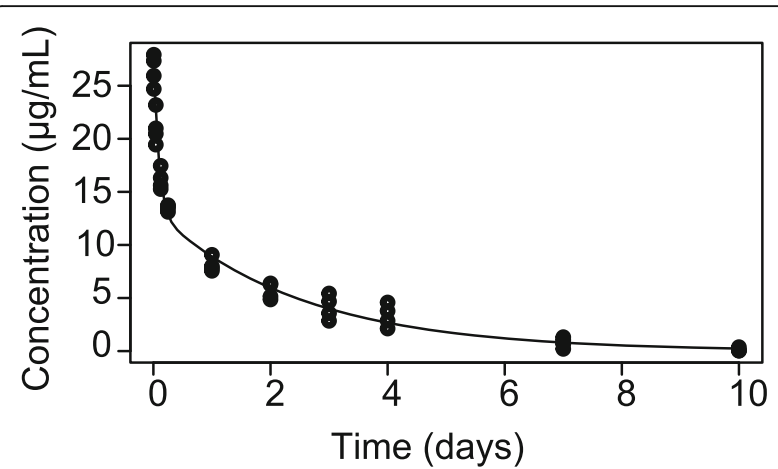

Fig. 5 Pharmacokinetic analysis of IRDye800CW-nimotuzumab in Balb/c mice. IRDye800CW-nimotuzumab was injected into BALB/C mice and blood was collected over time. The concentration of IRDye800CW-nimotuzumab in the blood was measured and plotted vs time. The data was fit using bi-exponential analysis

Hematological results are presented in Table 5, Table 6, and Additional File 6. A significant increase (IRDye800nimotuzumab $=2.2 \pm 0.5$, vehicle $=1.1 \pm 0.3$, baseline $=$ $\left.0.9 \pm 0.4 \times 10^{9} / \mathrm{L} ; p<0.01\right)$ was seen in the white blood cell count between IRDye800CW-nimtozumab and the control and vehicle at 2 days in female mice. This difference was not present at 14-days and was not present in male mice at 2-day or 14-days. There was no difference $(p>0.05)$ in any of the other hematology parameters.

\section{Effects in humans: meta-analysis of clinical trials with IRDye800CW}

We showed that IRDye800CW-nimotuzmab was safe in $\mathrm{BALB} / \mathrm{c}$ mice, however it has never been injected into humans. Furthermore, IRDye800CW in its carboxylate form is safe up to a concentration of $20 \mathrm{mg} / \mathrm{kg}$ when injected into rats ( $>500$-fold higher than used in this study) [10]. Also, since there have been numerous other IRDye $800 \mathrm{CW}$ probes used in clinical trials (Additional File 1), we performed meta-analysis of these other

Table 2 Specifications for IRDye800CW-nimotuzumab

\begin{tabular}{lll}
\hline Test parameter & Method & Acceptance Limits \\
\hline Visual appearance & Visual inspection & Clear, green solution, free from visible particulates \\
$\mathrm{pH}$ & $\mathrm{pH}$ meter & $6.5-7.5$ \\
Labelling ratio (Dye:Protein) & $\mathrm{UV}$ & $0.7-2.0$ \\
Strength $(\mathrm{mg} / \mathrm{mL})$ & $\mathrm{UV}$ & $10( \pm 20 \%)$ \\
Volume $(\mathrm{mL})$ & Weight & $5( \pm 10 \%)$ \\
Functional assay (Binding to cells) & Flow cytometry & $\mathrm{K}_{\mathrm{D}, \mathrm{sampl}} / \mathrm{K}_{\mathrm{D}, \mathrm{ref}} \times 100 \%<=200 \%$ \\
& & $>=50 \%$ \\
Identity and purity (protein) & Micro-capillary electrophoresis & $150 \mathrm{kDa}( \pm 10 \%)$ \\
& & Peak $>=95 \%$ \\
Purity (fluorescence) & SDS-PAGE & $>=90 \%$ \\
Bacterial endotoxin & USP $<85>$ & $<16 \mathrm{EU} / \mathrm{mL}$ \\
Sterility & USP $<71>$ & No growth \\
\hline
\end{tabular}


Table 3 Clinical chemistry results in male BALB/c mice injected with IRDye800CW-nimotuzumab

\begin{tabular}{|c|c|c|c|c|c|c|}
\hline \multirow[t]{3}{*}{ Parameter } & \multirow{3}{*}{$\begin{array}{l}\text { baseline } \\
\text { mean } \pm \mathrm{sd}\end{array}$} & \multicolumn{2}{|l|}{ day 2} & \multicolumn{2}{|l|}{ day 14} & \multirow{3}{*}{$\begin{array}{l}\text { (male) } \\
\text { unit }\end{array}$} \\
\hline & & vehicle & $\mathrm{Nz}-800 \mathrm{CW}$ & vehicle & $\mathrm{Nz}-800 \mathrm{CW}$ & \\
\hline & & \multicolumn{2}{|l|}{ mean $\pm s d$} & \multicolumn{2}{|l|}{ mean $\pm \mathrm{sd}$} & \\
\hline A:G Ratio & $1.5 \pm 0.1$ & $1.6 \pm 0.1$ & $1.6 \pm 0.2$ & $1.6 \pm 0.0$ & $1.7 \pm 0.1$ & \\
\hline ALT & $24.8 \pm 5.0$ & $27.6 \pm 4.0$ & $25.2 \pm 4.1$ & $27.2 \pm 3.3$ & $22.8 \pm 2.6$ & $U / L$ \\
\hline Albumin & $28.5 \pm 0.6$ & $29.4 \pm 1.1$ & $29.4 \pm 1.5$ & $30.8 \pm 1.8$ & $31.5 \pm 0.6$ & $g / L$ \\
\hline Alk Phos & $114 \pm 9$ & $131 \pm 4$ & $122 \pm 11$ & $123 \pm 3$ & $114 \pm 7$ & $\mathrm{U} / \mathrm{L}$ \\
\hline Amylase & $2893 \pm 836$ & $3167 \pm 247$ & $2883 \pm 127$ & $3130 \pm 223$ & $3692 \pm 764$ & $U / L$ \\
\hline CK & $310 \pm 127$ & $255 \pm 187$ & $217 \pm 78$ & $380 \pm 131$ & $356 \pm 154$ & $U / L$ \\
\hline Calcium & $2.4 \pm 0.3$ & $2.5 \pm 0.1$ & $2.5 \pm 0.1$ & $2.6 \pm 0.1$ & $2.5 \pm 0.1$ & $\mathrm{mmol} / \mathrm{L}$ \\
\hline Chloride & $105 \pm 1$ & $105 \pm 2$ & $105 \pm 0.8$ & $102 \pm 1.5$ & $104 \pm 1.7$ & $\mathrm{mmol} / \mathrm{L}$ \\
\hline Cholesterol & $3.3 \pm 0.2$ & $3.3 \pm 0.2$ & $3.4 \pm 0.1$ & $3.2 \pm 0.2$ & $3.2 \pm 0.2$ & $\mathrm{mmol} / \mathrm{L}$ \\
\hline Creatinine & $15.8 \pm 3.0$ & $15.5 \pm 2.6$ & $17.2 \pm 2.4$ & $17.8 \pm 2.3$ & $13.4 \pm 2.3$ & $\mu \mathrm{mol} / \mathrm{L}$ \\
\hline GLDH & $7.2 \pm 1.3$ & $9.8 \pm 1.9$ & $8.6 \pm 1.1$ & $7.0 \pm 0.7$ & $6.0 \pm 0.8$ & $\mathrm{U} / \mathrm{L}$ \\
\hline Globulin & $18.8 \pm 1.0$ & $19.0 \pm 1.2$ & $19.0 \pm 1.4$ & $19.2 \pm 1.1$ & $18.8 \pm 1.0$ & $g / L$ \\
\hline Glucose & $15.4 \pm 2.7$ & $12.8 \pm 1.7$ & $13.8 \pm 1.6$ & $12.8 \pm 2.8$ & $13.8 \pm 1.1$ & $\mathrm{mmol} / \mathrm{L}$ \\
\hline Lipase & $27.0 \pm 0.8$ & $27.4 \pm 2.5$ & $25.0 \pm 4.2$ & $28.4 \pm 2.3$ & $28.8 \pm 1.8$ & $\mathrm{U} / \mathrm{L}$ \\
\hline Magnesium & $1.1 \pm 0.1$ & $1.1 \pm 0.1$ & $1.1 \pm 0.1$ & $1.2 \pm 0.1$ & $1.1 \pm 0.1$ & $\mathrm{mmol} / \mathrm{L}$ \\
\hline Na:K Ratio & $35.5 \pm 1.3$ & $37.8 \pm 2.8$ & $41.5 \pm 3.7$ & $40.6 \pm 7.1$ & $38.5 \pm 1.9$ & \\
\hline Phosphorus & $2.9 \pm 0.3$ & $2.3 \pm 0.5$ & $2.5 \pm 0.3$ & $3.0 \pm 0.2$ & $2.6 \pm 0.3$ & $\mathrm{mmol} / \mathrm{L}$ \\
\hline Potassium & $4.2 \pm 0.2$ & $4.1 \pm 0.3$ & $3.6 \pm 0.3$ & $3.7 \pm 0.7$ & $4.0 \pm 0.2$ & $\mathrm{mmol} / \mathrm{L}$ \\
\hline Sodium & $151 \pm 2$ & $154 \pm 3$ & $150 \pm 2$ & $149 \pm 2$ & $151 \pm 2$ & $\mathrm{mmol} / \mathrm{L}$ \\
\hline Total Bilirubin & $0.1 \pm 0.2$ & $0.3 \pm 0.4$ & $0.7 \pm 0.4$ & $0.2 \pm 0.2$ & $0.4 \pm 0.5$ & $\mu \mathrm{mol} / \mathrm{L}$ \\
\hline Total Protein & $47.2 \pm 1.0$ & $48.4 \pm 0.6$ & $48.4 \pm 0.6$ & $50.0 \pm 2.8$ & $49.8 \pm 1.6$ & $g / L$ \\
\hline Urea & $8.7 \pm 0.2$ & $10.4 \pm 0.6$ & $9.6 \pm 1.1$ & $9.8 \pm 1.5$ & $9.0 \pm 1.5$ & $\mathrm{mmol} / \mathrm{L}$ \\
\hline
\end{tabular}

Abbreviations: Nz-800 IRDye800CW-nimotuzumab, A:G albumin to globulin, ALT alanine aminotransferase, alk phos alkaline phosphatase, $C K$ creatin kinase, GLDH glutamate dehydrogenase, $N a: K$ sodium to potassium

IRDye800CW probes in clinical trials to address the likely safety of IRDye800CW-nimotuzumab.

A search on clinicaltrials.gov for clinical trials with IRDye800CW resulted in 34 clinical trials (Additional File 7). Twenty-three were in-progress with ten in the USA, twelve in the Netherlands, and one in China, (Fig. 6a). Only three clinical trials have been terminated due to logistics, which involved IRDye800CW-cetuximab (Fig. 6a). The most predominant indication is head and neck cancer ( 8 clinical trials) followed by brain (5 clinical trials) and esophageal (4 clinical trials) (Fig. $6 \mathrm{~b}$ and Additional File 8). Of the 34 clinical trials identified, six are complete with one trial in the USA and five trials in the Netherlands.

These 34 clinical trials involve eight different imaging probes (Additional Files 7 and 9). The majority of trials $(n=13)$ involved IRDye800CW-bevacizumab (5 completed, 8 in-progress), which targets Vascular Endothelial Growth Factor (VEGF). The second most common probe IRDye800CW-pantitumumab targets EGFR and is being evaluated in six clinical trials. A second anti-EGFR probe IRDye $800 \mathrm{CW}$-cetuximab is being evaluated in two clinical trials; three clinical trials with this probe have been terminated due to logistics. Of the 34 clinical trials with IRDye800CW, no clinical trial has been withdrawn for safety reasons. Image-guided surgery is an expanding field with more clinical trials in-progress than completed (Fig. 6a and Additional File 9).

To assess the expected safety of IRDye800CWnimotuzumab, we performed a meta-analysis of adverse events (AEs) in patients treated with other IRDye $800 \mathrm{CW}$-conjugated antibodies. The analysis involved 102 patients from eight clinical trials that reported data on adverse events (Fig. 6c, Additional File 2) [15-22]. AEs that were potentially caused by the IRDye800CW-antibody were collected. MedDra version 21 was used to consolidate AEs based on low-level terms to the preferred term. No serious adverse events grade $3+$ were reported [15-22]. The majority 88/102 (86\%) of patients did not experience any AEs no serious (grade $3+)$ adverse events were reported. There was a single (1\%) grade 2 adverse event, pyrexia (fever). The most 
Table 4 Clinical chemistry results in female BALB/c mice injected with IRDye800CW-nimotuzumab

\begin{tabular}{|c|c|c|c|c|c|c|}
\hline \multirow[t]{3}{*}{ Parameter } & \multirow{3}{*}{$\begin{array}{l}\text { baseline } \\
\text { mean } \pm \text { sd }\end{array}$} & \multicolumn{2}{|l|}{ day 2} & \multicolumn{2}{|l|}{ day 14} & \multirow{3}{*}{$\begin{array}{l}\text { (female) } \\
\text { unit }\end{array}$} \\
\hline & & vehicle & Nz-800CW & vehicle & $\mathrm{Nz}-800 \mathrm{CW}$ & \\
\hline & & \multicolumn{2}{|l|}{ mean $\pm s d$} & \multicolumn{2}{|l|}{ mean $\pm s d$} & \\
\hline A:G Ratio & $2.0 \pm 0.1$ & $1.9 \pm 0.4$ & $2.1 \pm 0.3$ & $2.4 \pm 0.2$ & $2.3 \pm 0.2$ & \\
\hline ALT & $27.2 \pm 4.8$ & $41.5 \pm 21.1$ & $26.2 \pm 2.9$ & $23.8 \pm 7.2$ & $30.5 \pm 11.2$ & $U / L$ \\
\hline Albumin & $32.0 \pm 2.2$ & $31.8 \pm 3.4$ & $32.2 \pm 1.5$ & $32.0 \pm 0.7$ & $33.5 \pm 0.6$ & $g / L$ \\
\hline Alk Phos & $123 \pm 15$ & $150 \pm 20$ & $164 \pm 12$ & $128 \pm 8$ & $134 \pm 10$ & $\mathrm{U} / \mathrm{L}$ \\
\hline Amylase & $2332 \pm 292$ & $2537 \pm 139$ & $2819 \pm 480$ & $2335 \pm 140$ & $2307 \pm 123$ & $U / L$ \\
\hline CK & $413 \pm 182$ & $1248 \pm 391$ & $696 \pm 254$ & $805 \pm 661$ & $352 \pm 193$ & $U / L$ \\
\hline Calcium & $2.4 \pm 0.2$ & $2.4 \pm 0.1$ & $2.1 \pm 0.3$ & $2.5 \pm 0.1$ & $2.3 \pm 0.1$ & $\mathrm{mmol} / \mathrm{L}$ \\
\hline Chloride & $105 \pm 0.6$ & $101 \pm 6$ & $108 \pm 5$ & $106 \pm 2$ & $106 \pm 1$ & $\mathrm{mmol} / \mathrm{L}$ \\
\hline Cholesterol & $2.5 \pm 0.2$ & $2.3 \pm 0.3$ & $2.2 \pm 0.1$ & $2.3 \pm 0.2$ & $2.4 \pm 0.2$ & $\mathrm{mmol} / \mathrm{L}$ \\
\hline Creatinine & $17.8 \pm 3.0$ & $15.8 \pm 1.7$ & $13.5 \pm 1.7$ & $15.0 \pm 3.3$ & $16.2 \pm 1.3$ & $\mu \mathrm{mol} / \mathrm{L}$ \\
\hline GLDH & $10.0 \pm 2.9$ & $13.5 \pm 4.0$ & $13.0 \pm 1.7$ & $9.0 \pm 2.8$ & $8.2 \pm 3.0$ & $U / L$ \\
\hline Globulin & $15.8 \pm 0.5$ & $16.5 \pm 1.7$ & $15.5 \pm 1.7$ & $13.6 \pm 1.3$ & $14.5 \pm 1.3$ & $g / L$ \\
\hline Glucose & $15.2 \pm 1.6$ & $13.4 \pm 1.6$ & $12.9 \pm 1.5$ & $15.0 \pm 1.1$ & $14.8 \pm 0.6$ & $\mathrm{mmol} / \mathrm{L}$ \\
\hline Lipase & $25.8 \pm 3.6$ & $26.8 \pm 2.9$ & $26.0 \pm 2.2$ & $27.0 \pm 2.5$ & $26.8 \pm 2.2$ & $\mathrm{U} / \mathrm{L}$ \\
\hline Magnesium & $1.2 \pm 0.1$ & $1.1 \pm 0.1$ & $1.0 \pm 0.1$ & $1.1 \pm 0.1$ & $1.2 \pm 0.1$ & $\mathrm{mmol} / \mathrm{L}$ \\
\hline Na:K Ratio & $39.8 \pm 1.3$ & $33.5 \pm 5.8$ & $41.0 \pm 7.1$ & $42.4 \pm 4.6$ & $42.3 \pm 3.8$ & \\
\hline Phosphorus & $3.3 \pm 0.3$ & $2.7 \pm 0.4$ & $2.3 \pm 0.3$ & $2.8 \pm 0.4$ & $2.8 \pm 0.3$ & $\mathrm{mmol} / \mathrm{L}$ \\
\hline Potassium & $3.7 \pm 0.1$ & $4.3 \pm 0.7$ & $3.7 \pm 0.6$ & $3.6 \pm 0.3$ & $3.6 \pm 0.4$ & $\mathrm{mmol} / \mathrm{L}$ \\
\hline Sodium & $149 \pm 0.5$ & $144 \pm 5$ & $149 \pm 4$ & $150 \pm 2$ & $152 \pm 1.5$ & $\mathrm{mmol} / \mathrm{L}$ \\
\hline Total Bilirubin & $0.4 \pm 0.2$ & $0.0 \pm 0.0$ & $0.3 \pm 0.5$ & $0.2 \pm 0.3$ & $0.6 \pm 0.8$ & $\mu \mathrm{mol} / \mathrm{L}$ \\
\hline Total Protein & $47.8 \pm 2.2$ & $48.2 \pm 1.7$ & $47.8 \pm 1.3$ & $45.6 \pm 1.9$ & $48.0 \pm 1.4$ & $g / L$ \\
\hline Urea & $9.7 \pm 0.9$ & $10.9 \pm 1.4$ & $10.8 \pm 1.0$ & $10.2 \pm 0.7$ & $9.0 \pm 1.0$ & $\mathrm{mmol} / \mathrm{L}$ \\
\hline
\end{tabular}

Abbreviations: Nz-800 IRDye800CW-nimotuzumab, A:G albumin to globulin, ALT alanine aminotransferase, alk phos alkaline phosphatase, CK creatin kinase, GLDH glutamate dehydrogenase, $N a: K$ sodium to potassium

Table 5 Hematology analyses from male BALB/c mice injected with IRDye800CW-nimotuzumab

\begin{tabular}{|c|c|c|c|c|c|c|}
\hline \multirow[t]{3}{*}{ Parameter } & \multirow{3}{*}{$\begin{array}{l}\text { baseline } \\
\text { mean } \pm \text { sd }\end{array}$} & \multicolumn{2}{|l|}{ day 2} & \multicolumn{2}{|l|}{ day 14} & \multirow{3}{*}{$\begin{array}{l}\text { (male) } \\
\text { unit }\end{array}$} \\
\hline & & vehicle & $\mathrm{Nz}-800 \mathrm{CW}$ & vehicle & $\mathrm{Nz}-800 \mathrm{CW}$ & \\
\hline & & \multicolumn{2}{|l|}{ mean $\pm s d$} & \multicolumn{2}{|l|}{ mean $\pm s d$} & \\
\hline GR & $5.5 \pm 0.9$ & $2.7 \pm 1.0$ & $4.3 \pm 1.4$ & $2.7 \pm 0.7$ & $5.4 \pm 1.6$ & $\%$ \\
\hline $\mathrm{Hct}$ & $0.5 \pm 0.1$ & $0.5 \pm 0.1$ & $0.5 \pm 0.1$ & $0.5 \pm 0.0$ & $0.5 \pm 0.0$ & $L / L$ \\
\hline $\mathrm{Hgb}$ & $156 \pm 19$ & $146 \pm 20$ & $159 \pm 23$ & $166 \pm 4$ & $169 \pm 3$ & $g / L$ \\
\hline LY & $80.3 \pm 2.8$ & $85.2 \pm 4.5$ & $81.5 \pm 3.2$ & $87.5 \pm 1.6$ & $80.6 \pm 3.6$ & $\%$ \\
\hline $\mathrm{MCH}$ & $18.7 \pm 0.2$ & $19.1 \pm 0.3$ & $19.0 \pm 0.2$ & $18.9 \pm 0.1$ & $18.6 \pm 0.2$ & $g p$ \\
\hline $\mathrm{MCHC}$ & $321 \pm 1$ & $321 \pm 1$ & $322 \pm 1$ & $322 \pm 0.1$ & $322 \pm 0.1$ & $g / L$ \\
\hline MCV & $58.2 \pm 0.6$ & $59.4 \pm 0.8$ & $59.0 \pm 0.7$ & $58.8 \pm 0.2$ & $57.6 \pm 0.6$ & $\mathrm{fL}$ \\
\hline MO & $14.2 \pm 3.0$ & $12.1 \pm 3.8$ & $14.1 \pm 2.0$ & $9.8 \pm 1.7$ & $13.9 \pm 2.6$ & $\%$ \\
\hline Plt & $860 \pm 228$ & $900 \pm 164$ & $809 \pm 219$ & $923 \pm 90$ & $1001 \pm 78$ & $\times 10^{9} / \mathrm{L}$ \\
\hline $\mathrm{RBC}$ & $8.8 \pm 0.2$ & $8.9 \pm 0.4$ & $8.7 \pm 0.3$ & $8.7 \pm 0.1$ & $9.1 \pm 0.2$ & $\times 10^{12} / L$ \\
\hline RDW & $15.6 \pm 0.3$ & $15.9 \pm 0.8$ & $15.9 \pm 0.6$ & $16.9 \pm 1.9$ & $19.6 \pm 5.6$ & $\%$ \\
\hline WBC & $1.4 \pm 0.3$ & $2.1 \pm 0.7$ & $1.5 \pm 0.8$ & $1.6 \pm 1.0$ & $2.5 \pm 1.1$ & $\times 10^{9} / \mathrm{L}$ \\
\hline
\end{tabular}

Abbreviations: Nz-800 IRDye800CW-nimotuzumab, GR granulocytes, Hct hematocrits, hgb hemoglobin, $L Y$ lymphocytes, MCH mean corpuscular hemoglobin, $M C H C$ mean corpuscular hemoglobin concentration, $M C V$ mean corpuscular volume, $M O$ monocytes, Plt platelets, $R B C$ red blood cells, $R D W$ red blood cell distribution width, WBC white blood cell 
Table 6 Hematology analyses from female BALB/c mice injected with IRDye800CW-nimotuzumab

\begin{tabular}{|c|c|c|c|c|c|c|}
\hline \multirow[t]{3}{*}{ Parameter } & \multirow{3}{*}{$\begin{array}{l}\text { baseline } \\
\text { mean } \pm \text { sd }\end{array}$} & \multicolumn{2}{|l|}{ day 2} & \multicolumn{2}{|l|}{ day 14} & \multirow{3}{*}{$\begin{array}{l}\text { (female) } \\
\text { unit }\end{array}$} \\
\hline & & vehicle & Nz-800CW & vehicle & $\mathrm{Nz}-800 \mathrm{CW}$ & \\
\hline & & \multicolumn{2}{|l|}{ mean $\pm s d$} & \multicolumn{2}{|l|}{ mean \pm sd } & \\
\hline$\overline{G R}$ & $7.0 \pm N A$ & $4.6 \pm 1.4$ & $4.1 \pm 2.3$ & $2.8 \pm 0.3$ & $3.1 \pm 1.6$ & $\%$ \\
\hline $\mathrm{Hct}$ & $0.5 \pm 0.1$ & $0.4 \pm 0.1$ & $0.4 \pm 0.0$ & $0.5 \pm 0.1$ & $0.5 \pm 0.0$ & $\mathrm{~L} / \mathrm{L}$ \\
\hline $\mathrm{Hgb}$ & $160 \pm 22$ & $138 \pm 22$ & $140 \pm 12$ & $156 \pm 19$ & $161 \pm 13$ & $g / L$ \\
\hline LY & $77.8 \pm N A$ & $79.8 \pm 4.3$ & $82.9 \pm 2.3$ & $85.2 \pm 1.2$ & $83.6 \pm 6.9$ & $\%$ \\
\hline $\mathrm{MCH}$ & $18.9 \pm 0.3$ & $18.6 \pm 1.2$ & $17.2 \pm 0.3$ & $19.0 \pm 0.5$ & $19.2 \pm 0.2$ & gp \\
\hline $\mathrm{MCHC}$ & $322 \pm 1.3$ & $320 \pm 1.7$ & $321 \pm 0.6$ & $321 \pm 1.2$ & $322 \pm 0.5$ & $\mathrm{~g} / \mathrm{L}$ \\
\hline MCV & $58.7 \pm 1.0$ & $58.0 \pm 3.5$ & $53.7 \pm 1.0$ & $59.1 \pm 1.6$ & $59.5 \pm 0.6$ & $\mathrm{fL}$ \\
\hline MO & $15.2 \pm N A$ & $15.5 \pm 2.9$ & $13.0 \pm 1.2$ & $12.1 \pm 1.2$ & $13.4 \pm 5.3$ & $\%$ \\
\hline Plt & $703 \pm 173$ & $602 \pm 160$ & $453 \pm 318$ & $630 \pm 217$ & $711 \pm 137$ & $\times 10^{\wedge} 9 / \mathrm{L}$ \\
\hline RBC & $9.0 \pm 0.4$ & $8.2 \pm 0.5$ & $7.5 \pm 0.8$ & $8.8 \pm 0.2$ & $8.8 \pm 0.6$ & $\times 10^{\wedge} 12 / L$ \\
\hline RDW & $19.3 \pm 7.1$ & $19.1 \pm 1.2$ & $20.8 \pm 0.9$ & $15.7 \pm 0.7$ & $15.5 \pm 0.3$ & $\%$ \\
\hline WBC & $0.9 \pm 0.4$ & $1.1 \pm 0.3$ & $2.2 \pm 0.5$ & $1.9 \pm 1.5$ & $1.0 \pm 0.4$ & $\times 10^{\wedge} 9 / \mathrm{L}$ \\
\hline
\end{tabular}

Abbreviations: Nz-800 IRDye800CW-nimotuzumab, GR granulocytes, Hct hematocrits, $h g b$ hemoglobin, $L Y$ lymphocytes, $M C H$ mean corpuscular hemoglobin, $M C H C$ mean corpuscular hemoglobin concentration, $M C V$ mean corpuscular volume, $M O$ monocytes, Plt platelets, $R B C$ red blood cells, RDW red blood cell distribution width, WBC white blood cell

frequent grade 1 AEs occurred less than $2 \%$ [15-22]. In general, it was found that adverse events were similar to the parent antibody [7].

The parent antibody, nimotuzumab is registered in over 30 non-ICH countries. Post-marketing safety experience with nimotuzumab shows that serious adverse events (SAE) are rare and occur in less than $1 \%$ of patients [8].

\section{Discussion}

EGFR is overexpressed in a number of cancers. Many of these cancers are not responsive to therapies due to mutations and/or acquired resistance making surgical resection the only option. During resection of cancerous tissue, it can be difficult to distinguish between diseased and healthy tissue. Near-infrared fluorescence, imageguided surgery can be used to visualize cancerous tissues through specific binding of a fluorescent probe. EGFR is commonly over-expressed in a number of cancers [2]. Panitumumab and cetuximab are EGFR antibodies have been labeled with IRDye800CW and are currently in clinical trials for surgical navigation. Both conjugated antibodies have shown minimal toxicities [7, 13]. Nimotuzumab is an antibody that specifically binds to EGFR. Here, we conjugate IRDye $800 \mathrm{CW}$ to nimotuzumab to study the pre-clinical properties for use as a fluorescent probe in image-guided surgery.

The elimination half-life of IRDye800CWnimotuzumab calculated using both non-compartment and two-compartment modeling ( $38 \mathrm{~h}$ and $40.8 \mathrm{~h}$ ) in mouse was in the range of published results for nimotuzumab at doses of $100-400 \mathrm{mg}$ in humans $(34-75 \mathrm{~h}$ )
[23-25]. This is consistent with previously reported IRDye800CW-labeled EGFR antibodies showing their pharmacokinetic properties were similar to that of the parent antibody [7].

Acute and delayed toxicity of IRDye800CWnimtozumab was tested in BALB/c mice. There was an increase in the white blood cell count in the female mice at two days. By 14 days this difference was no longer present. These differences were not associated to histopathological findings or clinical observations of significance and therefore were not considered pathologically significant. There were no other differences in the hematology results of the other parameters and treatment groups.

The two most relevant probes to compare IRDye800CW-nimotuzumab with are IRDye800CWpanitiumamab and IRDye800CW-cetuximab as they also bind EGFR. The dose used in the preclinical toxicity studies was $15 \mathrm{mg} / \mathrm{kg}$ IRDye $800 \mathrm{CW}$-nimotuzumab $(1.2$ $\mathrm{mg} / \mathrm{kg}$ or $45 \mathrm{mg} / \mathrm{m}^{2}$ human equivalent dose). A dose at the upper range of clinical studies in humans using IRDye800CW-panitumumab $(0.06,0.5$, and $1 \mathrm{mg} / \mathrm{kg})$ or IRDye800CW-cetuximab $\left(2.5 \mathrm{mg} / \mathrm{m}^{2}, \quad 25 \mathrm{mg} / \mathrm{m}^{2}\right.$ and $62.5 \mathrm{mg} / \mathrm{m}^{2}$ ) [7]. In terms of safety, nimotuzumab when given alone as a therapy, has minimal skin toxicities compared to other EGFR antibodies where skin toxicities occur in the majority of the patients $(\sim 80 \%$ for cetuximab and $\sim 68 \%$ for panitumumab) and can be quite severe with some grade 3 reactions reported [9]. In studies with IRDye800CW-cetuximab and IRDye800CW-panitumumab, pre-injection with unlabeled antibody is performed prior to injection of the 


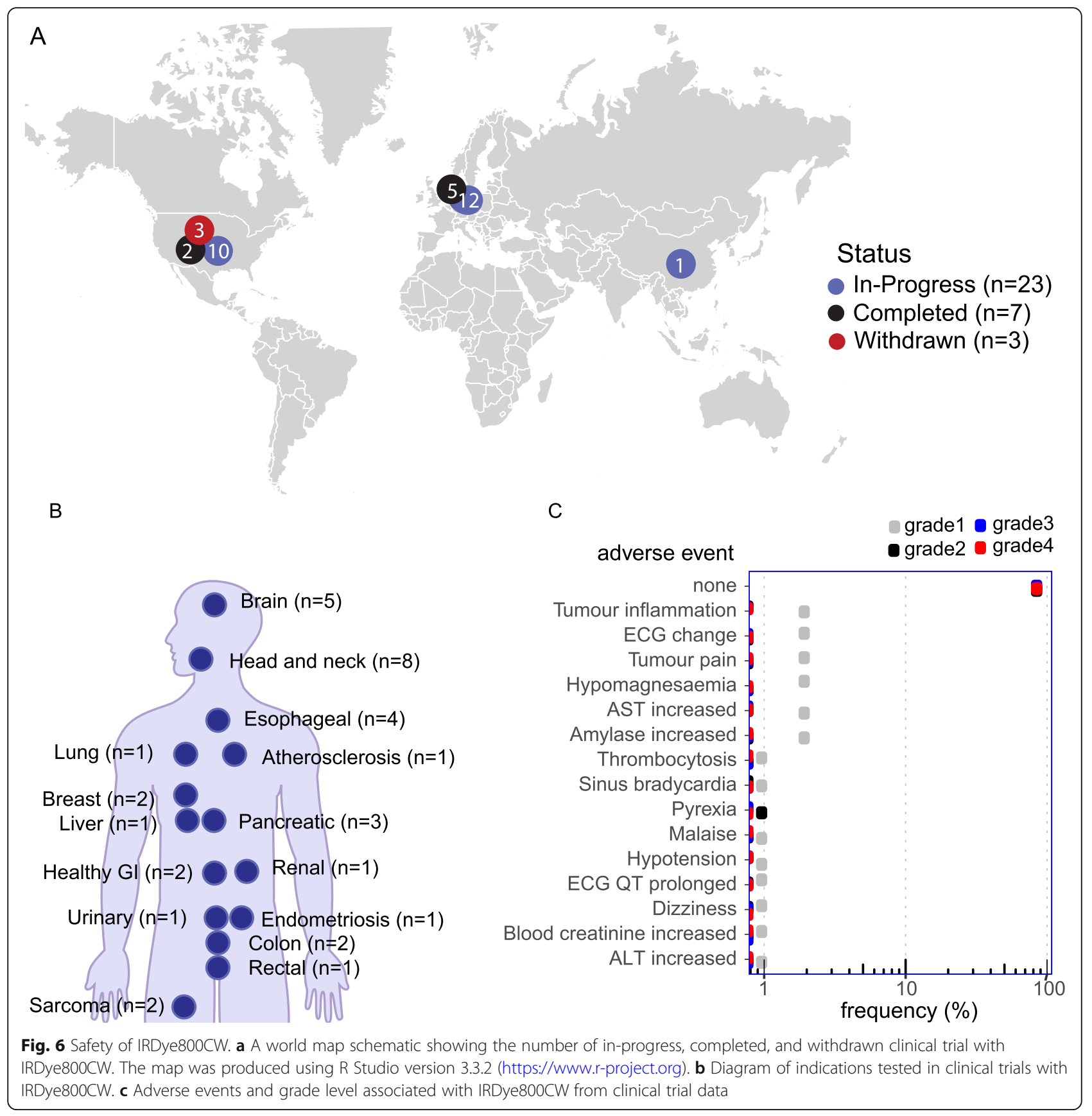

IRDye800CW probe to separate adverse events from the antibody with adverse events from the IRDye $800 \mathrm{CW}$ labeled antibody. Two infusion reactions have been observed for IRDye800CW-labeled cetuximab $(n=14)$ and none for IRDye800CW-labeled panitumumab $(n=15)$ [7]. No adverse reactions above grade 1 are observed for either of the IRDye800CW-labeled antibodies [7]. In general, the low toxicity observed for other anti-EGFR antibodies conjugated with IRDye800CW agrees with the toxicity results we observed in mice.
Safety studies with IRDye800CW-cetuximab and IRDye $800 \mathrm{CW}$ panitumumab show that the parent antibodies are similar to the IRDye $800 \mathrm{CW}$ labeled antibodies [7], indicating that labeling antibodies with IRDye $800 \mathrm{CW}$ does not increase their toxicity. In humans, use of the parent antibody, nimotuzumab has been shown in 38,629 patients, only $36(0.09 \%)$ had serious adverse events (SAE) related to the antibody [8]. In an observational prospective post registration clinical trial with 577 patients [8], only four SAE were reported 
(0.7\%). Adverse events (AE) are reported to be mild and occur in $10-15 \%$ of patients. The most frequently reported AE of a phase IV clinical trial with 127 patients were headache, increased transaminase, fever and skin rash; all were mild intensity [8]. It is important to note that the post marketing experience is from nimotuzumab administered at a clinical dose for multiple cycles. For image-guided surgery, nimotuzumab will be injected at a subclinical dose once.

\section{Conclusions: brief summary and potential implications}

Here, we show that IRDye800CW-nimotuzumab is a safe molecule with potential to be used in image-guided surgery. Currently approved EGFR antibodies are being used in clinical trials with great success. IRDye800CWnimotuzumab has a better safety profile than these parent antibodies. This study provides the basis for Sections 4,5 , and 6 of the Investigator's Brochure for a clinical trial application or investigational new drug application to use IRDye800CW-nimotuzumab in image-guided surgery of EGFR positive tumors.

\footnotetext{
Abbreviations

EGFR: Epidermal growth factor receptor; IB: Investigator's Brochure; CT: Computed tomography; PET: Positron emission tomography; MRI: Magnetic resonance imaging; NIR: Near infrared; CIM: Center of Molecular Immunology; PBS: Phosphate buffered saline; UACC: University animal care committee; CD-1: Cluster difference 1;

EDTA: Ethylenediaminetetraacetic acid; Gl: Gastrointestinal intestinal; Nz800: IRDye800CW-nimotuzumab; $\mathrm{t}_{1 / 2}$ : Half-life; A:G: Albumin to globulin; ALT: Alanine aminotransferase; alk phos: Alkaline phosphatase; CK: Creatine kinase; GLDH: Glutamate dehydrogenase; Na:K: Sodium to potassium; CBC: Complete blood counts; GR: Granulocytes; Hct: Hematocrits; hgb: Hemoglobin; LY: Lymphocytes; MCH: Mean corpuscular hemoglobin; MCHC: Mean corpuscular hemoglobin concentration; MCV: Mean corpuscular volume; MO: Monocytes; Plt: Platelets; RBC: Red blood cells; RDW: Red blood cell distribution width; WBC: White blood cell; VEGF: Vascular Endothelial Growth Factor; SAE: Serious adverse events; AE: Adverse events
}

\section{Supplementary Information}

The online version contains supplementary material available at https://doi. org/10.1186/s12885-021-08003-3.

Additional file 1. Clinical trials by probe. A table listing the clinical trials by probe with IRDye800CW and the number ( $\mathrm{n}$ ) of clinical trials.

Additional file 2. Schematic of how the meta-analysis on clinical trials with IRDye800CW was done and tables showing the clinical trials with IRD800CW with results published on pubmed.

Additional file 3. Mouse weights from toxicity studies. Graphs showing the weights of the mice used for the toxicity experiments prior to and during the experiments.

Additional file 4. Weight of mouse liver, kidney, and spleen from toxicity studies. Graphs showing the weights of the liver, spleen and kidney of the mice used for the toxicity experiments.

Additional file 5. Clinical chemistry results from the toxicity study. Sodium, potassium, sodium: potassium (Na:K) ratio, chloride, calcium, phosphorus magnesium, urea, creatinine, amylase, lipase, glucose, cholesterol, bilirubin, alkaline phosphatase (Alk Phos), alanine aminotransferase (ALT), glutamate dehydrogenase (GLDH), CK (creatine kinase), protein, albumin, globulin and albumin:globulin (A:G) ratio measurements from the IRDye800CW-nimotuzumab (800CW-Nz) toxicity studies.

Additional file 6. Hematology results from toxicity study. White blood cells $(\mathrm{WBC})$, lymphocytes (LY), monocytes (MO), granulocytes (GR), red blood cells (RBC) and red blood cell distribution width (RDW), hematocrits (Hct), platelets (Plt), haemoglobin (Hgb), mean corpuscular haemoglobin (MCH), mean corpuscular haemoglobin count (MCHC) and mean corpuscular volume (MCV) measurements from the IRDye800CWnimotuzumab (800CW-Nz) toxicity studies.

Additional file 7. Table 2: Clinical trials on clinicaltrials.gov accessed 20,190,422 search term: "800CW OR IRDYE800CW OR IRDYE".

Additional file 8. Indications of clinical trials with IRDye800CW. A table listing the clinical trials, indications and the number of indications ( $n$ ).

Additional file 9. Clinical trials by probe and trial status. A table listing clinical trials by probe of probes similar to IRDye800CW-nimotuzumab showing trials 'completed', 'in progress' and 'terminated' or 'withdrawn'.

\section{Acknowledgements}

Thanks to Kim Jett for information and guidance on blood collection and processing. We would like to thank Behlol Khan for help with the pharmacokinetic modeling.

\section{Authors' contributions}

All authors have read and approved the manuscript. W.B. designed and performed experiments (labeling, flow cytometry, cell culture, histopathology, complete blood counts, pharmacokinetics), analyzed data and wrote the manuscript. K.B. designed experiments, data mining/metaanalysis, analyzed data and reviewed and edited the manuscript. A.E. designed and performed experiments (xenografts, imaging, blood collection, dissection and pharmacokinetics), analyzed data. C.G. performed experiments (bioanalyzer, cell culture and histopathology). VRS helped with stability assays. DT and AC supplied nimotuzumab. JF performed histopathology analysis and reviewed the manuscript. H.F. helped supervise the study and reviewed the manuscript. C.R.G. supervised the study and reviewed the manuscript.

\section{Funding}

This work was funded by Western Diversification funding \#12939. The funding bodies had no role in study design, collection, analysis, interpretation of data, writing the manuscript, or decision to publish.

\section{Availability of data and materials}

All data generated or analyzed during this study are included in this published article [and its supplementary information files].

\section{Declarations}

Ethics approval and consent to participate

All animal protocols were approved by the University of Saskatchewan Animal Care Committee (protocol \# 20150048).

\section{Consent for publication}

Not applicable.

\section{Competing interests}

The authors declare that they have no competing interests.

\section{Author details}

'Department of Pathology and Laboratory Medicine, College of Medicine, University of Saskatchewan, Saskatoon, SK, Canada. ${ }^{2}$ Department of Medical Imaging, College of Medicine, University of Saskatchewan, Saskatoon, SK, Canada. ${ }^{3}$ Center of Molecular Immunology, Havana, Cuba. ${ }^{4}$ Department of Medical Imaging, Royal University Hospital, Saskatoon, SK, Canada. 
Received: 29 September 2020 Accepted: 2 March 2021

Published online: 12 March 2021

\section{References}

1. Yewale C, Baradia D, Vhora I, Patil S, Misra A. Epidermal growth factor receptor targeting in cancer: a review of trends and strategies. Biomaterials. 2013:34:8690-707.

2. Yarden $Y$, Sliwkowski MX. Untangling the erbb signalling network. Nat Rev Mol Cell Biol. 2001:2:127-37.

3. Tipirneni KE, Warram JM, Moore LS, Prince AC, de Boer E, Jani AH, et al. Oncologic procedures amenable to fluorescence-guided surgery. Ann Surg. 2017;266:36-47.

4. Pleijhuis RG, Graafland M, de Vries J, Bart J, de Jong JS, van Dam GM. Obtaining adequate surgical margins in breast-conserving therapy for patients with early-stage breast cancer: current modalities and future directions. Ann Surg Oncol. 2009;16:2717-30.

5. Rosenthal EL, Moore LS, Tipineni K, de Boer E, Stevens TM, et al. Sensitivity and specificity of Cetuximab-IRDye800CW to identify regional metastatic disease in head and neck cancer. Clin Cancer Res. 2017;23:4744-52.

6. Heath $\mathrm{CH}$, Deep NL, Sweeny L, Zinn KR, Rosenthal EL. Use of panitumumabIRDye800 to image microscopic head and neck cancer in an orthotopic surgical model. Ann Surg Oncol. 2012;19:3879-87.

7. Gao RW, Teraphongphom N, de Boer E, van den Berg NS, Divi V, Kaplan MJ, et al. Safety of panitumumab-IRDye800CW and cetuximab-IRDye800CW for fluorescence-guided surgical navigation in head and neck cancers. Theranostics. 2018:9:2488-95.

8. Saurez-Martinez G, Bencomo-Yane A. Nimotuzumab, effective immunotherapy for the treatment of malignant epithelial tumors. Biotecnol Apl. 2014;2:159-67.

9. Zhu Z. Targeted cancer therapies based on antibodies directed against epidermal growth factor receptor: status and perspectives. Acta Pharmacol Sin. 2007:28:1476-93.

10. Marshall MV, Draney D, Sevick-Muraca EM, Olive DM. Single-dose intravenous toxicity study of IRDye $800 \mathrm{CW}$ in Sprague-Dawley rats. Mol Imaging Biol. 2010;12:583-94.

11. Bernhard W, El-Sayed A, Barreto K, Gonzalez C, Hill W, Parada AC, et al. Near infrared fluorescence imaging of EGFR expression in vivo using IRDye800CW-nimotuzumab. Oncotarget. 2018;9:6213-27.

12. ICH. https://www.ich.org/home.html Accessed 24 May 2019.

13. R Core Team. R: a language and environment for statistical computing. Vienna: R Foundation for Statistical Computing; 2017.

14. Jaki T, Wolfsegger MJ. Estimation of pharmacokinetic parameters with the $R$ package PK. Pharm Stat. 2011;10(3):294-88.

15. Gao RW, Teraphongphom NT, van den Berg NS, Martin BA, Oberhelman NJ, et al. Determination of tumor margins with surgical specimen mapping using near-infrared fluorescence. Cancer Res. 2018;78:5144-454.

16. Rosenthal EL, Warram JM, de Boer E, Chung TK, Korb ML, et al. Safety and tumor specificity of cetuximab-IRDye800 for surgical navigation in head and neck cancer. Clin Cancer Res. 2015;21:3658-66.

17. Miller SE, Tummers WS, Teraphongphom N, van den Berg NS, Hasan A, et al. First-in-human intraoperative near-infrared fluorescence imaging of glioblastoma using cetuximab-IRDye800. J Neurooncol. 2018;139:135-43.

18. Hekman MC, Rijpkema M, Muselaers CH, Oosterwijk E, Hulsbergen-Van de Kaa CA, et al. Tumor-targeted dual-modality imaging to improve intraoperative visulaizaiton of clear cell renal cell carcinoma: a first in man study. Theranostics. 2018;8:2161-70.

19. Tummers WS, Miller SE, Teraphongphom NT, Gomez A, Steinberg I, et al. Intraoperative pancreatic cancer detection using tumor-specific multimodality molecular imaging. Ann Surg Oncol. 2018;25:1880-8.

20. Lamberts LE, Koch M, de Jong JS, ALL A, Glatz J, et al. Tumor-specific uptake of fluorescent bevacizumab-IRDye800CW microdosing in patients with primary breast cancer: A phase I feasibility study. Clin Cancer Res. 2017;23: 2730-41.

21. Harlaar NJ, Koller M, de Jongh SJ, van Leeuwen BL, Hemmer PH. Molecular fluorescence-guided surgery of peritoneal carcinomatosis of colorectal origin: a single-centre feasibility study. Lancet Gastroenterol Hepatol. 2016;1: 283-90.

22. Hartmans $E, J J J$ T, Linssen MD, PBG A, Koller M, et al. Potential red-flag identification of colorectal adenomas with wide-field fluorescence molecular endoscopy. Theranostics. 2018;8:1458-67.
23. Okamoto W, Yoshino T, Takahashi T, Okamoto I, Ueda S, Tsuya A, et al. A phase I, pharmacokinetic and pharmacodynamic study of nimotuzumab in japanese patients with advanced solid tumors. Cancer Chemother Pharmacol. 2013:72:1063-71.

24. Strumberg D, Schultheis B, Scheulen ME, Hilger RA, Krauss J, Marschner N, et al. Safety, efficacy and pharmacokinetics of nimotuzumab, a humanized monoclonal anti-epidermal growth factor receptor (EGFR) antibody, in patients with locally advanced or metastatic pancreatic cancer. Int J Clin Pharmacol Ther. 2010;48:473-5.

25. Kato K, Ura T, Koizumi W, Iwasa S, Katada C, Azuma M, et al. Nimotuzumab combined with concurrent chemoradiotherapy in japanese patients with esophageal cancer: a phase I study. Cancer Sci. 2018;109:785-93.

\section{Publisher's Note}

Springer Nature remains neutral with regard to jurisdictional claims in published maps and institutional affiliations.
Ready to submit your research? Choose BMC and benefit from:

- fast, convenient online submission

- thorough peer review by experienced researchers in your field

- rapid publication on acceptance

- support for research data, including large and complex data types

- gold Open Access which fosters wider collaboration and increased citations

- maximum visibility for your research: over $100 \mathrm{M}$ website views per year

At BMC, research is always in progress.

Learn more biomedcentral.com/submissions 